\title{
How a Chronic Headache Condition Became Resolved with One Session of Breathing and Posture Coaching
}

\author{
Erik Peper*, April Covell, and Nicole Matzembacker
}

San Francisco State University, San Francisco, California, USA

\begin{abstract}
This case example reports how a 32-year-old female student with chronic headaches since age 18 became headache-free after one session of breathing and posture coaching. She self-medicated and took between 2 and 10 Excedrin tablets per week. The class coaching session focused on shifting her habitual thoracic breathing to slower lower abdominal diaphragmatic breathing and posture retraining. While working at the computer, she used an app installed on her computer that provided visual and auditory feedback each time she slouched. She used the app 2-6 hours per day for 2 weeks, and each time in response to the slouching feedback she sat up erect and breathed slower and lower. After the first coaching session and for the following 14 weeks, she has been headache-free and not used any medications. After implementing breathing and posture changes, she also reported significant reduction in shoulder pain, back pain, depression, anxiety, and improvement in motivation. We recommend that when college students report headaches, anxiety, and gastrointestinal distress that they are first offered self-mastery interventions.
\end{abstract}

Keywords: headache; breathing; posture; awareness; electromyography

Citation: Peper, E., Covell, A., \& Matzembacker, N. (2021). How a chronic headache condition became resolved with one session of breathing and posture coaching. NeuroRegulation, 8(4), 194-197. https://doi.org/10.15540/nr.8.4.194

*Address correspondence to: Erik Peper, $\mathrm{PhD}$, Institute for Holistic Healing Studies, San Francisco State University, 1600 Holloway Avenue, San Francisco, CA 94132, USA. Email: epeper@sfsu.edu

Copyright: () 2021. Peper et al. This is an Open Access article distributed under the terms of the Creative Commons Attribution License (CC-BY).

\section{Edited by:}

Rex L. Cannon, PhD, SPESA Research Institute, Knoxville, Tennessee, USA

\section{Reviewed by:}

Rex L. Cannon, PhD, SPESA Research Institute, Knoxville, Tennessee, USA

Randall Lyle, PhD, Mount Mercy University, Cedar Rapids, lowa, USA

\section{Introduction}

Many students report experiencing anxiety, Zoom fatigue, neck and shoulder tension, abdominal discomfort, vision problems, and headaches, and the incidence has increased over the last few years as students spent more and more time in front of screens (Ahmed et al., 2021; Bauer et al., 2021; Charles et al., 2021; Kuehn, 2021; Peper et al., 2021). In many cases, the cause is more functional than structural, with headache pathogenesis indicating the linkage between bad posture, breathing, and headache (Elizagaray-Garcia et al., 2020; Schulman, 2002). Without awareness, students look down at their screens, maintain lowlevel muscle tension, and breathe shallowly, predominantly in their chests. When students become aware of these dysfunctional patterns and implement behavioral stress management skills as part of a semester-long class, they report a reduction in symptoms including irritable bowel syndrome, acid reflux, or anxiety (Peper et al., 2017a; Peper et al, 2016a). Sometimes, a single coaching session can be enough to improve health. This case report describes how a student with chronic headaches resolved her chronic headache in a coaching session.

The student was a 32-year-old woman who suffered from headaches which she self-labeled as migraines generally two or three times per week and took between 2 and 10 Excedrin tablets per week. As Excedrin contains $65 \mathrm{mg}$ of caffeine as well as 250 $\mathrm{mg}$ acetaminophen and $250 \mathrm{mg}$ of aspirin, the chronic headaches may have been partially caused by caffeine withdrawal which would get resolved by taking more Excedrin (Greben et al., 1980). Acetaminophen may also be harmful to liver function (Bauer et al., 2021). She reported that headaches first began when she was 18, after using digital 
devices which encouraged her to slouch as she looked down. Although she describes herself as healthy, she reports having high anxiety and experiencing occasional depression.

\section{The Behavioral Coaching Intervention}

At the beginning of the class, the student approached the instructor and said that she was not feeling well and had a severe headache. As she was talking, the instructor noticed that she was breathing in her chest without any abdominal movement, her shoulders were held tight, her posture was slightly slouched, and her hands were cold. She was unaware of what was happening in her body. The instructor offered to guide her through some practices that she might find useful to reduce her headaches.

Working Hypothesis. The headaches most likely were tension headaches and not migraines. They may be the result of neck and shoulder tension which is maintained during chest breathing and the slouched head forward body posture. If she could change her posture, relax her neck and shoulders, and breathe diaphragmatically so that the lower abdomen widens during inhalation, most likely her shoulder and neck tension would decrease. Therefore, by changing posture from a slouched to upright position combined with slower diaphragmatic breathing, the muscle tension would be reduced and the headaches would decrease.

\section{Breathing and Posture Changes}

With verbal and tactile coaching, she learned slower diaphragmatic breathing, where she gently and slowly exhaled by making a sound of pssssssst (exhaling through pursed lips), which tends to activate transverse and oblique abdominal muscles as well as tighten the pelvic floor muscles so that her lower abdomen would slightly come in at the end of the exhalation (Peper et al., 2016b). The inhalation occurred by allowing the lower abdomen and pelvic floor to relax so that the abdomen would expand in 360 degrees $^{1}$. This expansion of the abdomen allowed the air to flow in effortlessly without lifting her chest. Part of the purpose for breathing this way is that many people unknowingly tighten the pelvic floor muscle and lower abdominal wall as a protective pattern when they curl slightly forward in a protective position. This position also tends to contract the muscles of the neck and shoulders.

\footnotetext{
${ }^{1}$ She could easily allow her abdomen to expand, as she never had abdominal injury or surgery and was not selfconscious of letting her waist widen (Peper et al., 2015).
}

To allow breathing to occur effortlessly, she would need to sit upright so that the abdomen had space to expand during inhalation (Peper et al., 2020). In addition, the clothing around her waist would need to be loosened to allow her abdomen to enlarge and expand in 360 degrees (MacHose \& Peper, 1991). For numerous participants, it is challenging to allow the abdomen to expand as they are self-conscious about their abdomen getting bigger or as an unconscious learned response to avoid pain after having had abdominal surgery (Peper et al., 2015).

The upright position allowed her to sit tall and erect, in which the back of head reaches upward towards the ceiling while relaxing and feeling gravity pulling her shoulders downward, at the same time relaxing her hips and legs. While practicing the slower breathing in the relaxed upright position, she was asked to sense or imagine feeling a flow down and through her arms and out her hands as she exhaled. After a few minutes, she felt her headache reduce in intensity and also noticed that her hands had slightly warmed. After this short coaching intervention, she went back to her seat and continued to practice the relaxed effortless breathing while sitting upright and allowing her shoulders to melt downward.

\section{Demonstration of Muscle Tension While Feeling Relaxed}

During the same class session, she volunteered to have her trapezius muscle monitored with electromyography (EMG). Even though she felt relaxed, the EMG indicated that her muscles were not relaxed. With a few minutes of EMG feedback exploration, she discovered that she could relax her shoulder muscles by feeling them being heavy and melting.

\section{Home Practice with a Posture App}

As part of the class home laboratory assignment, she was assigned a self-study for 2 weeks with a posture feedback app, Dario Desktop. The app uses the computer or laptop camera to monitor posture. When the person slouches, the app provides visual feedback in a small window on the computer screen and/or an auditory signal as shown in Figure 1.

The steps in this self-study were first to monitor her symptoms for 3 days and then install the posture feedback application on her laptop to provide feedback whenever she slouched. The posture feedback reminded her to practice better posture everyday while working on her computer and integrated short breaks of stretching and standing when using the computer for an extended period of time. 
Figure 1. Posture Feedback to Signal to Participant that the Person Is Slouching.

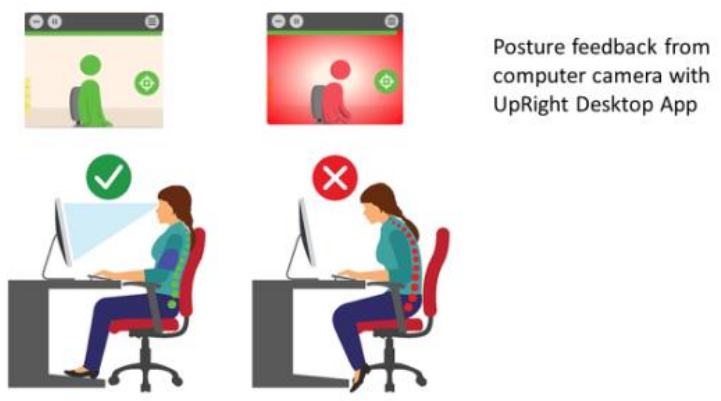

Each time the feedback signal indicated she slouched, she would sit up and change her posture, breathe lower and slower and relax her shoulders. She also monitored what factors triggered the slouching. Additionally, she added daily reminders to her phone to remind her of her posture and added reminders to stretch and stand after each hour of studying. After 2 weeks she recorded her symptoms for 3 days for the post-assessment.

\section{Results}

The chronic headache condition which had been present for 14 years disappeared, and she has not used any medication since the first day of class. At the 14 week follow-up she continues to be headache free. In addition, she reported after 2 weeks that her shoulder discomfort and pain, back discomfort and pain, depression, anxiety, and lack of motivation decreased as shown in Figure 2.

Figure 2. Changes in Symptoms After Implementing Posture Feedback for 2 Weeks.

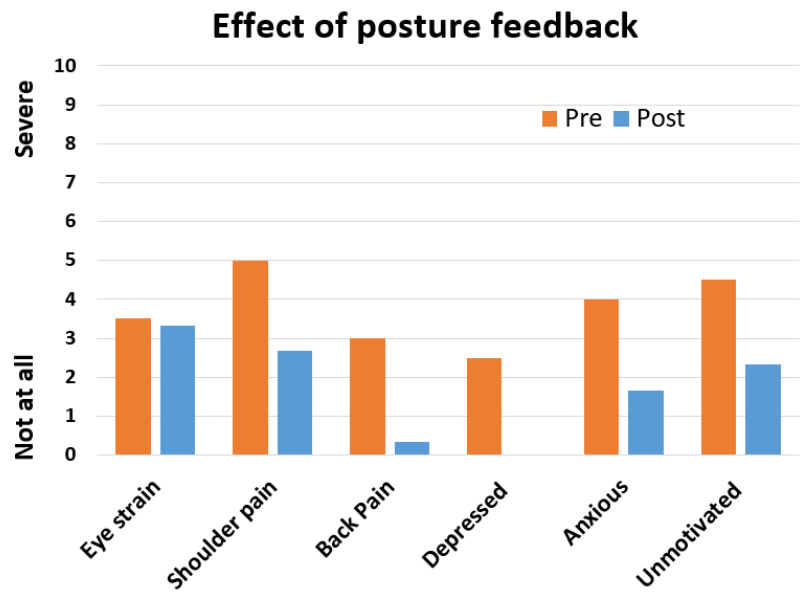

She used the upright app every time she opened her laptop at home, as often as 3-5 times per day (roughly 2-6 hours). In addition, when she felt the beginning of discomfort or thought she should take medication, she would adjust her posture and breathe. While using the app, she identified numerous factors that were associated with slouching, as shown in Figure 3.

Figure 3. Behaviors Associated with Slouching.

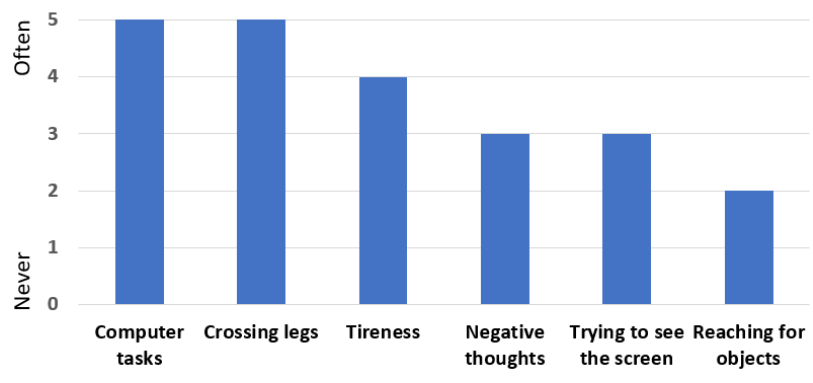

\section{Discussion}

Using posture feedback as a tool at home to remind the person to practice sitting tall and relaxing the shoulders, while practicing slower diaphragmatic breathing, eliminated a chronic headache condition. The posture feedback also improved mood, resulting in less depression and anxiety. The decrease in depression, anxiety, and lack of motivation may be the direct result of posture change-since a slouched position allows easier access to hopeless, helpless, and powerless thought and in the upright position the subject felt increased energy and easier access to empowering and positive thoughts (Peper et al., 2017b; Tsai et al., 2016; Veenstra et al., 2017; Wilson \& Peper, 2004). Most likely the success occurred because the participant actually implemented the changes in her behavior. As she noted, "Although it was distracting to be reminded all the time about my posture, it did decrease my neck pain. With the pain reduction, I was able to sit at the computer longer and felt more motivated."

The combination of slower lower abdominal breathing with the upright posture reversed her protective/defensive body position which often tightens the muscle in the lower abdomen and pelvic floor and the shoulders and neck (pressing your knees together and curling your shoulder forward). The upright posture creates position of empowerment and trust by which the lower abdomen can expand. In addition, the upright 
posture allows easier access to positive thoughts and reduces recall of hopeless, powerless, or defeated memories. It is also possible that caffeine withdrawal was a cofactor in evoking headaches (Küçer, 2010). By eliminating the medication, she also eliminated the triggering of the caffeine withdrawal headaches.

This case example suggests that before medications are prescribed, health care providers may want to teach simple behavioral techniques which the student can implement during the day instead of prescribing medication. Yet, in most cases, students report that the usual medical treatment provided is medication. We recommend that when college students report headaches, anxiety, and gastrointestinal distress that they are first offered self-mastery interventions (Peper et al., 2016a). Useful interventions may include slower and lower diaphragmatic breathing, erect upright posture, stress management, cognitive behavior therapy, and health-promoting lifestyles modifications such as regular sleep, exercise, and healthier diet.

\section{Acknowledgment}

We thank Yifat Fundoiano-Hershcovitz, PhD, Scientific and Clinical Director Dario Health for her constructive feedback on the manuscript.

\section{Author Disclosure}

Authors have no grants, financial interests, or conflicts to disclose.

\section{References}

Ahmed, S., Akter, R., Pokhrel, N., \& Samuel, A. J. (2021). Prevalence of text neck syndrome and SMS thumb among smartphone users in college-going students: A crosssectional survey study. Journal of Public Health, 29, 411-416. https://doi.org/10.1007/s10389-019-01139-4

Bauer, A. Z., Swan, S. H., Kriebel, D., Liew, Z., Taylor, H. S., Bornehag, C.-G., Andrade, A. M., Olsen, J., Jensen, R. H., Mitchell, R. T., Skakkebaek, N. E., Jégou, B., \& Kristensen, D. M. (2021). Paracetamol use during pregnancy - A call for precautionary action. Nature Reviews Endocrinology, 17, 757-766. https://doi.org/10.1038/s41574-021-00553-7

Charles, N. E., Strong, S. J., Burns, L. C., Bullerjahn, M. R., \& Serafine, K. M. (2021). Increased mood disorder symptoms, perceived stress, and alcohol use among college students during the COVID-19 pandemic. Psychiatry Research, 296, 113706. https://doi.org/10.1016/j.psychres.2021.113706

Elizagaray-Garcia, I., Beltran-Alacreu, H., Angulo-Díaz, S., Garrigós-Pedrón, M., \& Gil-Martínez, A. (2020). Chronic primary headache subjects have greater forward head posture than asymptomatic and episodic primary headache sufferers: Systematic review and meta-analysis. Pain Medicine, 21(10), 2465-2480. https://doi.org/10.1093/pm /pnaa235
Greden, J. F., Victor, B. S., Fontaine, P., \& Lubetsky, M. (1980). Caffeine-withdrawal headache: A clinical profile. Psychosomatics, 21(5), 411-413, 417-418. https://doi.org /10.1016/S0033-3182(80)73670-8

Küçer, N. (2010). The relationship between daily caffeine consumption and withdrawal symptoms: A questionnairebased study. Turkish Journal of Medical Sciences, 40(1), 105-108. https://doi.org/10.3906/sag-0809-26

Kuehn, B. M. (2021). Increase in myopia reported among children during COVID-19 lockdown. JAMA, 326(11), 999. https://doi.org/10.1001/jama.2021.14475

MacHose, M. \& Peper, E. (1991). The effect of clothing on inhalation volume. Biofeedback and Self-regulation, 16, 261265. https://doi.org/10.1007/BF01000020

Peper, E., Booiman, A., Lin, I.-M., Harvey, R., \& Mitose, J. (2016b). Abdominal SEMG feedback for diaphragmatic breathing: A methodological note. Biofeedback, 44(1), 42-49. https://doi.org/10.5298/1081-5937-44.1.03

Peper, E., Gilbert, C. D., Harvey, R. \& Lin, I.-M. (2015). Did you ask about abdominal surgery or injury? A learned disuse risk factor for breathing dysfunction. Biofeedback, 43(4), 173-179. https://doi.org/10.5298/1081-5937-43.4.06

Peper, E., Lin, I.-M., Harvey, R., \& Perez, J. (2017b). How posture affects memory recall and mood. Biofeedback. 45(2), 36-41. https://doi.org/10.5298/1081-5937-45.2.01

Peper, E., Mason, L., Harvey, R., Wolski, L., \& Torres, J. (2020). Can acid reflux be reduced by breathing? Townsend Letter, The Examiner of Alternative Medicine, 445/446, 44-47. https://www.townsendletter.com/article/445-6-acid-refluxreduced-by-breathing/

Peper, E., Mason, L., \& Huey, C. (2017a). Healing irritable bowel syndrome with diaphragmatic breathing. Biofeedback, 45(4), 83-87. https://doi.org/10.5298/1081-5937-45.4.04

Peper, E., Miceli, B., \& Harvey, R. (2016a). Educational model for self-healing: Eliminating a chronic migraine with electromyography, autogenic training, posture, and mindfulness. Biofeedback, 44(3), 130-137. https://doi.org /10.5298/1081-5937-44.3.03

Peper, E., Wilson, V., Martin, M., Rosegard, E., \& Harvey, R. (2021). Avoid Zoom fatigue, be present and learn. NeuroRegulation, 8(1), 47-56. https://doi.org/10.15540 /nr.8.1.47

Schulman, E. A. (2002). Breath-holding, head pressure, and hot water: An effective treatment for migraine headache. Headache, 42(10), 1048-1050. https://doi.org/10.1046/j.15264610.2002.02237.x

Tsai, H.-Y., Peper, E., \& Lin, I.-M. (2016). EEG patterns under positive/negative body postures and emotion recall tasks. NeuroRegulation, 3(1), 23-27. https://doi.org/10.15540 /nr.3.1.23

Veenstra, L., Schneider, I. K., \& Koole, S. L. (2017). Embodied mood regulation: the impact of body posture on mood recovery, negative thoughts, and mood-congruent recall. Cogntion and Emotion, 31(7), 1361-1376. https://doi.org $/ 10.1080 / 02699931.2016 .1225003$

Wilson, V. E., \& Peper, E. (2004). The effects of upright and slumped postures on the generation of positive and negative thoughts. Applied Psychophysiology and Biofeedback, 29(3), 189-195.

/b:apbi.0000039057.32963.34

https://doi.org/10.1023

Received: October 18, 2021

Accepted: November 2, 2021

Published: December 31, 2021 